\title{
Biografias e processos de saúde-doença
}

\begin{abstract}
Allan de Gouvêa PEREIRA ${ }^{1}$
Resumo:

Em uma sociedade individualista, a vivência dos processos de saúde-doença atende a uma série de requisitos sociais em relação às suas formas de subjetivação. Tal panorama é justificado pelo fato de que a experiência de quem enfrentou uma determinada enfermidade ganha notoriedade e é valorizada como uma narrativa autêntica e, por que não, exemplar. Nessa perspectiva, este trabalho objetiva se configurar como um estudo teórico capaz de refletir sobre as escolhas, as reivindicações e os fatores culturais que envolvem os agentes sociais em seus estados de saúde e doença, a partir de quatro relatos biográficos. São mobilizados conceitos teóricos relativos às ideologias vigentes, tais como estigma, desvio, memória, projeto e agência. O estudo mostra que esses relatos repercutem as ideologias individualistas modernas e reclamam maior "agência" sobre as escolhas pessoais.
\end{abstract}

Palavras-chave: Biografias. Saúde. Doença. Individualismo. Subjetividade.

\section{Biographies and health-disease processes}

\begin{abstract}
:
In an individualistic society, the experience of health-disease processes meets a series of social requirements in relation to their forms of subjectivity. This context is justified by the fact that the experience of those who faced a certain disease gets notoriety and is valued as an authentic and exemplary narrative. In this perspective, this work aims to be a theoretical study capable of reflecting about the choices, demands and cultural factors that involve social agents in their health and illness conditions, based on four biographical reports. Theoretical concepts related to the current ideologies are mobilized, such as stigma, deviance, memory, project and agency. This study shows that these reports reflect modern individualist ideologies and demand greater "agency" over personal decisions.
\end{abstract}

Keywords: Biographies. Health. Disease. Individualism. Subjectivity.

\section{Biografías y procesos salud-enfermedad}

\begin{abstract}
:
En una sociedad individualista, la experiencia de los procesos salud-enfermedad responde a una serie de requisitos sociales en relación a sus formas de subjetividad. Tal panorama se justifica por el hecho de que la experiencia de quienes enfrentaron una determinada enfermedad cobra notoriedad y se valora como una narrativa auténtica y, por qué no, ejemplar. En esta perspectiva, este trabajo pretende configurarse como un estudio teórico capaz de reflexionar sobre las elecciones, demandas y factores culturales que involucran a los agentes sociales en sus estados de salud y enfermedad, a partir de cuatro relatos biográficos. Se movilizan conceptos teóricos relacionados con las ideologías actuales, como estigma, desviación, memoria, proyecto y agencia. Este estudio muestra que estos relatos reflejan ideologías individualistas modernas y exigen una mayor "agencia" sobre las elecciones personales.
\end{abstract}

Keywords: Biografías. Salud. Enfermedad. Individualismo. Subjetividad.

\footnotetext{
1 Jornalista, mestre em Comunicação pela Universidade Federal de Juiz de Fora e doutor em Informação e Comunicação em Saúde pelo Programa de Pós-Graduação em Informação e Comunicação em Saúde da Fundação Oswaldo Cruz. E-mail: allan_pereira_jf@hotmail.com.
} 
"E trabalhemos para mostrar como é preciso tomar consciência de nós mesmos”. Marcel Mauss (2003, p. 397).

\section{Introdução}

Um processo de doença numa trajetória de vida parece representar, simbolicamente, um conjunto de reconfigurações nas subjetividades contemporâneas. Especialmente nos dias atuais, em que o perfil epidemiológico das sociedades aponta para um aumento da incidência e prevalência das chamadas doenças crônico-degenerativas (em decorrência do aumento da expectativa de vida), é razoável considerar que se assinalam, culturalmente, algumas modificações no sentido da experiência de um adoecimento. Isso pode determinar, por exemplo, as escolhas e as práticas sociais que caracterizam os modos de ser e estar no mundo, principalmente em relação ao corpo e à saúde, nossos objetos de interesse investigativo.

Sobretudo quando se trata de uma enfermidade degenerativa, temos a noção de estarmos diante de uma situação limítrofe, isto é, que nos coloca próximos ao fim da vida e talvez esteja aqui o mote para voltar a atenção à interioridade, em processos de reconhecimento de si. Para além do construto social presente na concepção da doença nos dias atuais, cabe considerar ainda que o perfil epidemiológico das sociedades modernas está associado ao estilo de vida adotado pelas populações, segundo o saber biomédico. Nesse sentido, o diagnóstico de uma doença e o seu tratamento reivindicam, para o doente e as pessoas à sua volta, uma série de considerações sobre os aspectos biográficos, na medida em que atribui ao adoecimento um sentido de "divisor de águas" na história dessas vidas. Por conseguinte, essa reflexão está imbricada no acionamento de dispositivos mnemônicos, quando um passado próximo ou distante parece ter relação com o presente que é caracterizado pela vivência da enfermidade.

Soma-se a isso a concepção de que, nesse cenário, o desenvolvimento da noção de indivíduo conduziu à ideologia do individualismo, cujas raízes histórico-intelectuais, especialmente após a Revolução Francesa, promoveram a centralidade do indivíduo (em oposição ao modelo de sujeitos coletivos) e sua pretensa capacidade de exercer a liberdade e a autonomia. A valorização das experiências singulares, que autenticam e legitimam as narrativas de si, indicam que o indivíduo parece se configurar como uma categoria analítica representativa dos fenômenos sociais modernos. É preciso levar em conta, na esteira do pensamento de Dumont (1985, p. 79), que a sociedade é o conceito no qual as "pessoas se associam" por meio de um "contrato": "de um modo geral, e no plano social propriamente 
dito, já não há lugar para a ideia de comunidade. Ela é suplantada pela liberdade do indivíduo".

Importa perceber que, diante dessas reconfigurações sociais, as fronteiras entre público e privado se tornam ainda mais porosas (em oposição ao modelo burguês), estabelecendo as "tiranias da visibilidade", que tornam "visível nada menos que a intimidade de cada um e de qualquer um" (SIBILIA, 2016, p. 126-127). No caso das doenças, a subjetividade é reconfigurada pelo nascimento da clínica médica que "inaugurou um saber específico sobre cada indivíduo, além de uma série de práticas que focalizavam a experiência do sofrimento de cada sujeito em particular. [...] O foco, portanto, deslizou-se da doença para o doente" (SIBILIA, 2016, p. 146-147).

Nesse sentido, o intuito deste trabalho é analisar as mudanças das subjetividades atravessadas por processos de saúde-doença, a partir de quatro relatos (auto)biográficos. Elencamos algumas categorias que podem ser importantes para entender as escolhas e as formas idiossincráticas relatadas nesses produtos, segundo determinadas matrizes de ordem ideológica que podem ser delineadas nos contextos em que se inserem. Essas categorias, que serão apresentadas mais detidamente nos itens subsequentes, versam sobre proposições teórico-conceituais, a exemplo das noções de estigma (GOFFMAN, 1978), desvio (BECKER, 2008), memória (POLLAK, 1989, 1992; HALBWACHS, 1990), projeto (VELHO, 1999, 2013) e agência (ORTNER, 2007).

Portanto, diante de um estudo teórico em torno das transformações da subjetividade no mundo moderno, objetivamos identificar tais conceitos em quatro obras literárias que são caracterizadas pela dimensão biográfica, em face do regime de doença; não necessariamente na perspectiva daquele que é diagnosticado com uma enfermidade, mas pelo registro de um indivíduo que, de alguma maneira, é ou se sente afetado por um processo de adoecimento. Dessa forma, nosso estudo analisa quatro relatos diferentes: o de (1) Jo Spence (1995), uma fotógrafa inglesa "transgressora", cujo trabalho se destaca pela politização e pela ruptura em relação aos paradigmas de gênero, classe, saúde e corpo, mas que aqui será analisado, especialmente, pela exposição da sua própria experiência com o câncer de mama; o de (2) Heloísa Seixas (2007), uma jornalista carioca que publicou um livro para relatar a vivência com a sua mãe, diagnosticada aos 79 anos de idade com o mal de Alzheimer; o de (3) Clara Larson, uma assistente social lésbica estadunidense, que teve câncer de mama em 1979 e em 1997, e que foi objeto de estudo da pesquisadora Maren Klawiter (2008); e, por último, (4) o 
de André Gorz (2012), um intelectual marxista e sartriano que viveu boa parte de sua vida na França com Dorine, a quem escreve uma carta de amor, próximo ao fim da vida, depois de muitos anos que ela passou a conviver com uma doença dolorosa, ocasionada por um erro médico, e que também desenvolveu mais tarde câncer de endométrio.

Reconhecendo as distinções que demarcam esses produtos, nosso intuito não é um estudo de caráter comparativo, mas de "pontos de contato", por meio da exemplificação como estratégia analítica. Em outras palavras, a ideia é perceber quais são as estruturas socioculturais relativas à saúde que, no mundo ocidental, são materializadas e valoradas em narrativas de cunho biográfico; com vistas a compreender, potencialmente, como as redes de identificação construídas orquestram escolhas e conformam subjetividades.

De maneira geral, é possível antecipar que, nos quatro casos, o narrador estabelece um relato sobre o sofrimento, de maneira significativa, como parte considerável de sua trajetória de vida, mesmo quando a dor ocasionada pela doença é a do outro. Essa concepção se materializa de modo mais evidente, como se verá, nos registros de Heloísa Seixas e de André Gorz, que falam do outro para, na verdade, voltarem-se para si mesmos. Prova disso é a alternância, operacionalizada quase que de forma natural, entre os usos da primeira pessoa (do singular e do plural) e da terceira pessoa.

\section{Sujeitos modernos e identidades estigmatizadas ou desviantes}

A reivindicação pública percebida pela necessidade de narrar a si mesmo se configura como um processo ideológico característico da modernidade. Nessa perspectiva, entenderíamos o que a pesquisadora Sarlo (2007, p. 15) chamou de "guinada subjetiva" e, assim, especialmente nas experiências relativas a eventos-limite, essa narrativa assume um novo ethos terapêutico, como se a necessidade de falar publicamente do seu sofrimento (mas, principalmente, de sua superação) fosse um imperativo moral. "Escrever, isto é, ausentar-se do mundo e de si mesmo para, eventualmente, fazer disso a matéria de elaborações literárias [...] Escrevia para conjurar a angústia. Não importava o quê; eu era um escrevedor" (GORZ, 2012, p. 22). A ação da escrita ou de vocalização do que se passa na esfera da intimidade é um elemento constitutivo dessa ideologia moderna, que supostamente tem um papel importante no processo de compreensão do próprio eu: “Quando escrevo, tenho sempre a sensação de estar à deriva, levada por esses controladores, os personagens, que me obrigam a deixar aflorar coisas que gostaria de esconder. Porque sem dúvida escrever é um pouco como 
sonhar - ou enlouquecer" (SEIXAS, 2007, p. 37, grifo da autora).

De forma adicional, a impressão da doença, na construção das subjetividades modernas, se torna um atributo indissociável daquilo que a constitui como pessoa, não podendo mais se dissociar do que ela é ou de como ela se percebe vivendo em sociedade. A experiência do adoecimento funciona como uma espécie de amálgama totalizador da vivência.

\begin{abstract}
A identidade pessoal, então, está relacionada com a pressuposição de que ele pode ser diferençado de todos os outros e que, em torno desses meios de diferenciação, podem-se apegar e entrelaçar, como açúcar cristalizado, criando uma história contínua e única de fatos sociais que se torna, então, a substância pegajosa à qual vêm-se agregar outros fatos biográficos (GOFFMAN, 1978, p. 67).
\end{abstract}

Temos, assim, um sugestivo trabalho reflexivo no que diz respeito às identidades fluidas ou instáveis, porque foram atravessadas pela experiência de um sofrimento físico e que, em muitos casos, as colocaram diante do fim da vida. A percepção social desse acontecimento ou dessas subjetividades pode conduzir o debate para a noção de que estamos diante de uma situação em que o indivíduo está inabilitado para aceitação social plena (GOFFMAN, 1978, p. 7) ou cuja aceitação apresenta condições ou formas de tratamento particulares, visto que "a sociedade estabelece meios de categorizar as pessoas e o total de atributos considerados como comuns e naturais para os membros de cada uma dessas categorias" (GOFFMAN, 1978, p. 11). O estigma, segundo o autor, é o que se dá quando o seu efeito de descrédito é muito grande, podendo ser um defeito, uma fraqueza ou uma desvantagem, e que constitui uma discrepância específica entre a "identidade social virtual" (aquela oriunda de uma imputação feita por um retrospecto em potencial) e a "identidade social real" (categoria e atributos que prova possuir na realidade) (GOFFMAN, 1978, p. 12). Para tanto, é necessário que o estigmatizado tenha as mesmas crenças sobre identidade que os demais, para entender o que significa ter um estigma particular.

No caso de uma doença curável, o alcance da superação seria uma forma de inspiração equivalente à construção de uma persona heroica, que passou por uma tragédia, mas que se redimiu. Seria interessante problematizar que, nos grupos de ajuda mútua de pacientes, a retórica é padronizada no sentido da positividade/esperança e se assemelha aos valores cultuados pela sociedade, de um modo geral; uma vez que isso é repercutido, frequentemente, pelos meios de comunicação. Em um contexto no qual também se valoriza, sobremaneira, a retórica da liberdade e da autonomia, alguns grupos materializam uma censura que não é verbalizada, mas que não permite que outros discursos, que exaltem a falha 
e o sofrimento, sejam discutidos ou visibilizados.

Na consecução do pensamento de Goffman, Becker (2008, p. 40) estabelece que o sentimento mobilizador desse pertencimento, nos respectivos nichos sociais, seria aquele em que a pessoa que comete um ato desviante "faz do desvio uma maneira de viver, organiza sua identidade em torno de um padrão de comportamento desviante". Desse modo, o desvio daria aos "outsiders" uma sensação de "estarem no mesmo barco":

A partir desse sentimento de destino comum, da necessidade de enfrentar os mesmos problemas, desenvolve-se uma cultura desviante: um conjunto de perspectivas e entendimentos sobre como é o mundo e como se deve lidar com ele - e um conjunto de atividades rotineiras baseadas nessas perspectivas. O pertencimento a um grupo desse tipo solidifica a identidade desviante (BECKER, 2008, p. 48).

O entendimento central em torno do desvio está condicionado, portanto, ao conjunto de regras criado por determinado grupo social. No caso da saúde, por exemplo: "quando está funcionando de modo eficiente, sem experimentar nenhum desconforto, o organismo humano é considerado 'saudável'. Quando não funciona com eficiência, há doença. Diz-se que o órgão ou função em desajuste é patológico" (BECKER, 2008, p. 18). Dentre as possibilidades conceituais, Becker comenta que alguns sociólogos trabalham com um modelo de desvio baseado, em essência, nas noções médicas de saúde e doença, buscando perceber se em uma (parte da) sociedade, há processos vigentes que tendem a diminuir a sua estabilidade, reduzindo a sua chance de sobrevivência. Por isso, é interessante considerar que a percepção de saúde, numa organização social qualquer, tem um recorte de caráter sociológico.

Becker (2008, p. 25) enriquece o debate ao complexificar a questão, quando afirma que "o grau em que um ato será tratado como desviante depende também de quem o comete e de quem se sente prejudicado por ele. Regras tendem a ser aplicadas mais a algumas pessoas que a outras". Isso porque o sujeito moderno está vinculado a diversos contextos concomitantemente $^{2}$, embora exista o temor, como Goffman (1978) previa, de que os estigmatizados sejam definidos unicamente pelo seu estigma ou de que o desvio seja o "status principal" do indivíduo, para usar a expressão cunhada por Becker (2008, p. 43). De outro lado, existem outros recortes que devem ser levados em consideração em qualquer tipo de identidade que se deseja compreender, pois os indivíduos também possuem características de estrato social, gênero, escolarização, posicionamento político, sexualidade etc. O processo de

\footnotetext{
2 “....um sujeito não essencial, constitutivamente incompleto e, portanto, aberto a identificações múltiplas, em tensão com o outro, o diferente, através de posicionamentos contingentes que é chamado a ter" (ARFUCH, 2010, p. 80).
} 
determinação das regras sociais não é, então, uma tarefa simples, que gera rápido consenso; elas são, ao contrário, altamente diferenciadas por conta das referidas características (BECKER, 2008).

A reflexão teórica sobre os diferentes contextos de um mesmo sujeito tem relevo na experiência de Clara Larson, em virtude de sua militância no movimento feminista, que ainda estava alcançando suas primeiras conquistas quando do seu primeiro diagnóstico, em 1979. Sua identidade de mulher lésbica, ativista e estadunidense foi importante, de acordo com a análise de Klawiter (2008), para verificar que os regimes e as experiências de doença também podem ser transformados pelos movimentos sociais. Apesar de estarem começando a mudar, algumas questões ainda eram evidentes no regime da doença no fim da década de 1970, que configurariam as condições identitárias dessas personagens:

[...] o isolamento, a normalização e a falta de poder dos pacientes; a hegemonia das premissas normativas de gênero e heteronormativas sobre a personificação feminina, sua atratividade e sexualidade; a invisibilidade das mulheres com câncer de mama e mastectomizadas no espaço público (a despeito das divulgações públicas de várias celebridades); e a ausência de uma identidade de grupo (KLAWITER, 2008, p. 230).

O trabalho da fotógrafa Jo Spence, nesse cenário, propõe romper com o imaginário estigmatizador da doença neoplásica e, exatamente por isso, culmina com a sua estratégia de secundar o que ela chamou de fototerapia - entendendo o sofrimento do câncer como um processo que demanda um trabalho de natureza psíquica, possivelmente por causa, em boa parte, dos sentidos sociais predominantes em torno da doença: "quando eu soube que tinha câncer de mama, atravessei um caleidoscópio de sentimentos. Fui da depressão ao desespero, depois a fantasias suicidas, depois à raiva, e então de volta à desesperança" (SPENCE, 1995, p. 130).

Para além do "estigma" de não ter um corpo saudável, a transgressão de Jo também se traduz na sua escolha inicial de buscar tratamentos alternativos, recusando, inclusive, os procedimentos tradicionais - o que é retratado no seu trabalho artístico, como uma reivindicação política em defesa dos direitos dos pacientes, que poderiam, para ela, até mesmo buscar os conhecimentos disponíveis em outras culturas. Ela alerta, por exemplo, para a importância de dissociar os sentidos inerentes à doença dos de seu tratamento. Isso é assinalado por ela provavelmente porque a mastectomia ou a queda dos cabelos (consequência comum da quimioterapia) podem ser vistos como os "símbolos de estigma", na 
concepção de Goffman (1978, p. 53), na medida em que oferecem a informação social para que os demais o reconheçam.

A reunião de sujeitos que compartilham determinada particularidade é encontrada na narrativa de André Gorz, ao relatar a busca da cura por sua amada, que sofria de aracnoidite ${ }^{3}$ - uma doença causada pela substância "lipiodol", que foi injetada nela durante uma cirurgia de hérnia de disco. Dorine sofria de paralisia e tinha dores atrozes. Diante dessa situação, conforme registra André em sua narrativa epistolar endereçada à esposa, ela teria entrado em contato com uma "rede internacional de doentes que se ajudam mutuamente trocando informações e conselhos depois de terem batido de frente, assim como você [Dorine], com a ignorância e às vezes a má vontade da classe médica" (GORZ, 2012, p. 47). Os "não informados", desse modo, seriam agentes nos quais não se pode confiar totalmente, porque podem disseminar o preconceito e, ainda, em alguns casos, apresentar falta de tato profissional. De outro lado, entre os "informados", haveria um mecanismo de trocas simbólicas, um acordo tácito, que garante a manutenção do grupo e de seus integrantes, num regime de confiança e de confidencialidade.

Na história de Heloísa, o estigma aparece, por exemplo, na autossugestão recorrente de ela mesma estar enlouquecendo. Contudo, a loucura está mais materializada na doença da mãe, que seria mais uma forma de a autora estar convivendo proximamente com um transtorno mental. Em um de seus relatos, ela conta que a mãe parecia conservar, a despeito do Alzheimer, uma persona social, dizendo lembrar-se de pessoas de que, segundo Heloísa, ela certamente não se lembrava (SEIXAS, 2007, p. 109). Isso ilustra a noção de que os condicionamentos sociais, pela necessidade de "comportar-se bem", não se apagam facilmente, mesmo diante de uma enfermidade que causa, dentre outros sintomas, o não reconhecimento de si mesmo. O caso da saúde mental, no plano social, requer uma análise sociológica mais apurada em relação à noção de estigma/desvio, porque exige mais atenção para perceber os símbolos. Um exemplo é quando Heloísa leva sua mãe ao dentista e, no elevador do prédio comercial, no meio de várias pessoas desconhecidas, a segunda começa a gritar e a solução encontrada pela filha foi fazer gesto de silêncio e dizer: "Psiu! Aqui não é lugar de gritar. Fica quieta, senão o moço vai brigar”, como quem se dirige a uma criança, confirmando a informação social ou o "símbolo de estigma" da doença de sua mãe. De modo genérico, podemos observar que a nossa convenção social se inclina a deslegitimar a fala do louco, assim como ocorre com relação à fala da criança e à do bêbado.

\footnotetext{
${ }^{3}$ Inflamação da membrana aracnoide, uma das que envolve os nervos da medula espinhal (ARACNOIDITE, [s.d.).
} 


\section{Projeto, memória e agência}

O senso de subjetividade desembocou no individualismo como ideologia hegemônica e, dentro das disputas simbólicas que se operam na esfera social, subsistem dois conceitos importantes: projeto e agência. Essas referências epistemológicas apresentam dimensões fundamentais para compreender as orientações que levam os indivíduos a fazer determinadas escolhas de vida, e não outras. Nosso intuito não é discutir definições possíveis para os conceitos, mas reconhecer limites e potencialidades dessas propostas para a compreensão das formações que caracterizam as subjetividades contemporâneas, principalmente em face da ocorrência de uma doença.

De início, importa considerar que há uma distinção substancial entre uma identidade já dada socialmente e outra que é fruto de uma trajetória de opções e escolhas. Por esse atributo, a junção das noções de memória e projeto na constituição da identidade requer o entendimento de que há uma "persistência da unidade englobante fixada através de mitos, narrativas que reforçam o pertencimento dos indivíduos biológicos àquelas unidades" (VELHO, 2013, p. 64), sendo que a unidade englobante estaria bem representada pela memória. De acordo com o antropólogo brasileiro, em todas as sociedades ocorre um processo de individuação (inserção do lugar do indivíduo na sociedade e desempenho de seus papéis sociais). Porém, apenas nas que florescem as ideologias individualistas, a individualização atribui ao indivíduo um valor socialmente significativo, básico da cultura. Por conseguinte, a noção de biografia não está mais contida, mas é constituinte da sociedade. Segundo o autor, esses processos sociais possibilitam a formulação e condução de projetos.

De acordo com esse pensamento, é possível verificar que se trata de um terreno propício à modelização, formação de paradigmas culturais que conformam os elementos sociológicos, políticos e econômicos dessas sociedades individualistas. No entanto, essa concepção não neutraliza as possibilidades de decisão dos sujeitos, pois que o contrário seria uma visão ingênua e simplista de nossa sociedade. Esse raciocínio é, ao fim e ao cabo, a base fundamental do conceito de projeto. A sensação de liberdade é, inclusive, um elemento importante da padronização cultural. "De qualquer forma o processo de individualização não se dá fora de normas e padrões por mais que a liberdade individual possa ser valorizada. [...] Ou seja, há regras para a individualização" (VELHO, 1999, p. 25).

Nesse sentido, também é importante levar em conta que a implementação de projetos 
não pode se dar de maneira isolada, individual, "pura". Por isso, "não é um fenômeno puramente interno, subjetivo. Formula-se e é elaborado dentro de um campo de possibilidades, circunscrito histórica e culturalmente" (VELHO, 1999, p. 27) e é, por assim dizer, inextricavelmente dinâmico, porque tem uma dimensão biográfica, localizada no tempo e na sociedade e, em consequência, sujeita a transformações de natureza diversa. Em suma, o projeto, para Gilberto Velho (1999, p. 31), “deve ser uma tentativa consciente de dar um sentido ou uma coerência a essa experiência fragmentadora", não podendo ser entendido sem suas indissociáveis relações de poder e, por isso, é uma teorização de natureza eminentemente política.

De maneira análoga, a condução de projetos deve ser percebida também pela noção de agência, cujo termo, de acordo com Ortner (2007), já indica que se trata de um elemento autônomo, individualista e que, desse modo, todos os atores sociais a têm. Não obstante, contextos de solidariedade (como os grupos que compartilham um estigma) atenuam as formas egoístas e individualistas; mas subsiste uma teia assimétrica de relações de poder que envolve os agentes, configurando desigualdades, competições. Importa-nos o debate que diz respeito às forças exercidas nos atores sociais em relação às demandas de suas vidas, que determinam as escolhas e estabelecem dominações e resistências.

Em seu uso provavelmente mais comum, o termo "agência" pode ser praticamente sinônimo das formas de poder que as pessoas têm à sua disposição, de sua capacidade de agir em seu próprio nome, de influenciar outras pessoas e acontecimentos e de manter algum tipo de controle sobre suas próprias vidas. Agência, neste sentido, é pertinente tanto no caso da dominação quanto no da resistência. As pessoas em posições de poder "têm" - legitimamente ou não - o que poderia ser considerado "muita agência", mas também os dominados sempre têm certa capacidade, às vezes muito significativa, de exercer algum tipo de influência sobre a maneira como os acontecimentos se desenrolam. Portanto, resistência também é uma forma de "agência de poder" [...] (ORTNER, 2007, p. 64).

A obsessão pelo biográfico nos coloca diante da necessidade de entender os atributos agenciais do tempo passado, visto que as narrativas de si são, essencialmente, mnemônicas. ${ }^{4}$ Isso está patente nos quatro exemplos literários selecionados, justamente porque nosso intuito analítico é

[...] localizar experiências suficientemente significativas para criar fronteiras simbólicas. Nos estudos de grupos desviantes sempre é um problema crucial perceber se e quando indivíduos que partilham preferências por

\footnotetext{
4 "Parece haver um temor de esquecer: uma apreensão face às possíveis falhas de memória, um pavor sugerido pela ameaça de que as nossas lembranças possam ser apagadas e que, então, o passado desapareça de vez" (SIBILIA, 2016, p. 155-156).
} 
comportamentos condenados ou discriminados desenvolvem uma identidade comum e solidariedade (VELHO, 1999, p. 16).

A narrativa biográfica alusiva à experiência de uma doença vai estabelecer, por meio das memórias individual e coletiva, sentidos que podem atenuar ou agravar o sofrimento. Trata-se sempre de uma construção seletiva, fragmentada (não necessariamente intencional) e que é enquadrada de acordo com os interesses em jogo, com uma "agência", para determinar o que deve ser esquecido ou lembrado (POLLAK, 1989, 1992). Esse pensamento também reflete o que Bourdieu (1996, p. 183) chamou de "ilusão biográfica", visto que a produção de uma história de vida integra a atribuição de sentidos artificiais, que cria uma ilusão retórica que, no nível teórico, daria conta de uma experiência comum da vida como unidade ou totalidade, que insere o sujeito num campo social determinado ${ }^{5}$.

No caso do câncer, por exemplo, os velhos sentidos que ainda lhe são atribuídos (morte, mutilação, sofrimento), muito provavelmente, estão vinculados às experiências de um sem número de pessoas que tiveram contato com a doença, em alguma circunstância de suas vidas, ou que se escoram no depoimento de outras. "Certamente, se nossa impressão pode apoiar-se não somente sobre nossa lembrança, mas também sobre a dos outros, nossa confiança na exatidão de nossa evocação será maior, como se uma mesma experiência fosse recomeçada, não somente pela mesma pessoa, mas por várias" (HALBWACHS, 1990, p. 16). Um exemplo está presente na narrativa da jornalista carioca, que reconhece limites e, assim, tenta fortalecer determinadas imagens construídas mnemonicamente, operando o dispositivo discursivo da sinceridade: "Talvez a memória me falhe, mas a lembrança que tenho daquele aposento é ainda mais triste que a do resto do apartamento. E foi naquele quarto sombrio que encontrei minha mãe. Ou o monstro em que se transformara minha mãe” (SEIXAS, 2007, p. 119-120).

$\mathrm{Na}$ gestão da vida dos personagens acometidos pela doença, a construção de memórias (auto)biográficas parece ligar-se a um ideal de autonomia, um valor tão eminente que, ao que tudo indica, se torna a principal reivindicação dos doentes. Esse valor é reclamado pelos familiares que acompanham o enfrentamento da doença, que também se veem dependentes do sistema, da autoridade médica e dos valores sociais que parecem excluir ou marginalizar as vidas postas à prova.

O caso de Jo Spence é o que representa mais eficazmente esse universo teórico. O seu projeto é justamente basilar uma rejeição, uma resistência à ortodoxia médica e sugerir

\footnotetext{
${ }^{5}$ Em perspectiva semelhante, Arfuch (2010, p. 82) propõe a ideia de que só é possível obter uma "totalidade imaginária”.
} 
uma nova forma de entender as reverberações dos processos de saúde-doença; embora, em uma macrovisão, seu projeto ampliado é o de uma emancipação de gênero, de saber e, em uma palavra, de vida. Ela se vale, para isso, de tratamentos alternativos; atuando na defesa de uma maior agência dos pacientes no sentido de garantir a sua autonomia para fazer escolhas e, ainda, desconstruir as imagens que as pessoas fazem deles como heróis ou vítimas. "De qualquer forma, em minha própria jornada através da doença eu seriamente considerei meus direitos ao suicídio e à eutanásia [...] Finalmente, e em uma nota positiva, eu sinto que é importante tentar ajudar os outros a compartilharem uma nova filosofia de saúde" (SPENCE, 1995, p. 123, grifo da autora). As coerções sociais delimitam a agência dos indivíduos, o que pode influenciar os sentimentos e a constituição de um novo ethos, e nessa direção a autora propõe suas ideias tidas como "transgressoras". O paradoxo do individualismo moderno está ilustrado exatamente aqui, haja vista o processo de modelização dos costumes e, paralelamente, a valoração da liberdade associada à responsabilização individual.

Ortner (2007) aponta as questões de gênero como uma das principais no sentido de revelar as assimetrias de agência e isso aparece notoriamente nas narrativas de Spence e de Klawiter. A biografia realizada pela segunda reverbera as transformações das conduções dos projetos e das mudanças do poder de agência dos indivíduos com câncer, especialmente das mulheres, pela falta de visibilidade e pelos preconceitos - potencializados, no caso de Larson, em decorrência da sexualidade - que culminou, inclusive, no apoio à edificação de um movimento estruturado.

O desenvolvimento de organizações feministas e lésbicas do câncer criaram novos espaços sociais, solidariedades, subjetividades, além de expandir os tipos de experiências de doença disponíveis dentro do segundo regime do câncer de mama. Mas experiências individuais, memórias, personalidades e perspectivas também formam a experiência da doença (KLAWITER, 2008, p. 242).

O relato de Gorz, após ele e a mulher esgotarem todas as possibilidades no sentido de vencer a doença pelas descobertas da ciência, registra a intencionalidade da esposa nos jogos travados com a enfermidade:

Você não tinha mais nada a esperar da medicina. Recusava-se a se acostumar com os analgésicos e a depender deles. Decidiu então assumir o controle do seu corpo, da sua doença, da sua saúde; tomar o poder sobre a sua vida em vez de deixar a tecnociência médica tomar o poder sobre a sua relação com o seu corpo e consigo mesma (GORZ, 2012, p. 47). 
Agência e projeto são limitados, sobremaneira, na experiência de Heloísa e de sua mãe. Todos os projetos que ambas tinham, provavelmente, foram significativamente alterados na manhã de sábado em que a mãe de Heloísa, recém-chegada de uma excursão, havia se arrumado, de maneira impecável, para “descer para tomar café", achando que ainda estava no hotel. Essa dimensão de instabilidade que diz respeito ao projeto, justamente pelo fato de estar ligado ao futuro, está mais fortemente delineada no caso de uma patologia como o Alzheimer, porque observa os fatores contingenciais sócio-históricos e porque também é uma característica da vida, que torna a sociedade e seus estudos complexos. $\mathrm{O}$ atravessamento da doença também reconfigura, no caso da mãe da jornalista, muitos outros fatores de seu poder de agência, pela mudança na personalidade (teria se tornado cruel, conservadora e, por vezes, agressiva).

Além do mais, a crise que se opera numa experiência com o Alzheimer representa o apavorante medo das sociedades modernas em relação ao esquecimento, porque não lembrar significa perder a sua própria identidade, o seu modo de estar no mundo. Não é por acaso que os indivíduos procuram, então, cada vez mais, ancorar-se em instrumentos materiais e simbólicos, tecnológicos e abstratos, para jamais perderem-se de si mesmos. Por isso também se avolumam, com velocidade considerável, os gêneros biográficos na internet, em particular, e nas mídias, de um modo geral (SIBILIA, 2016; ARFUCH, 2010).

\section{Considerações finais}

Este trabalho analisou os fatores socioculturais que, via de regra, demarcam as narrativas biográficas de pessoas que, em determinado momento, perceberam que a sua trajetória de vida foi completamente modificada pela ocasião de um adoecimento. Esses eventos fazem emergir questões que tangenciam temas coletivos que se conectam a outras áreas, a exemplo da conquista de direitos e da luta por autonomia e igualdade. A iminência da proximidade da morte suscita reflexividades sobre o sentido da experiência e aponta para a necessidade de autorreconhecimento e de políticas identitárias.

O que se identificou nessa investigação, porém, foi que, apesar de reivindicarem direitos emancipatórios, além de desejarem exercer maior "agência" sobre decisões pessoais, os narradores de biografias repercutem ideologias dominantes, sobretudo em função dos mecanismos inerentes ao individualismo moderno. Os atos de memória, operados inevitavelmente nesses relatos, são, desse modo, construídos de maneira a atender àquilo que 
o outro espera ler/ouvir e contemplar os seus interesses subjetivos. Esse endosso do que é hegemônico visibiliza, por exemplo, uma modelização dos costumes e das escolhas, uma tendência à construção social de pessoa como seres psicológicos, que devem se conciliar com eles mesmos (e com a sociedade) através do relato público. A esfera pública seria, então, de maneira vulgar, o novo divã.

É fundamental destacar, em todo esse cenário, a autoridade exercida por aquele que narra essas trajetórias de vida, porque "viveu na pele" ou "viu com os próprios olhos". Essa narrativa autentica e atribui valor de verdade à "história de vida à qual deu vida", decidindo o que deveria ser lembrado, esquecido ou silenciado. Por consequência, esses relatos guardam dimensões de enquadramento e ficcionalidade, por mais que a retórica mobilizada tente transportar o leitor/ouvinte à ambiência dos acontecimentos narrados.

Os estudos sinalizam também a fragmentação, que é um dos aspectos que caracterizam a vida em uma sociedade individualista moderna. Fragmentos de uma experiência concreta são adotados como elementos generalizantes, que dão forma e sentido à existência. E isso sempre se dá de forma seletiva, seja para atender aos projetos políticos dominantes ou para exercer alguma possibilidade de agência, visto que um ideal de liberdade e autonomia ainda parece prevalecer, embora as estruturas estabeleçam novas e sutis formas de modelização dos comportamentos e das escolhas individuais. Essas estratégias de narrar a si mesmo vêm à cata de preencher um vazio ou de dar completude à experiência, por intermédio de uma pretensão de totalidade.

Por fim, o argumento construído não pretende esgotar o debate e encerrar a visão sobre o sujeito moderno ou sobre os processos de subjetivação do adoecer. Porém, é crível reconhecer que, dentro desse universo analítico, se pode identificar alguns dos principais valores prevalentes na cultura ocidental. De todo modo, essa reflexão e os próprios objetos analisados são dinâmicos e subjetivos em si mesmos, o que assinala a necessidade de uma análise contínua, em face de sua complexidade intrínseca. 
Referências

ARFUCH, Leonor. O espaço biográfico: dilemas da subjetividade contemporânea. Rio de Janeiro: EdUERJ, 2010.

BECKER, Howard. Outsiders: estudos de sociologia do desvio. Rio de Janeiro: Zahar, 2008.

BOURDIEU, Pierre. A ilusão biográfica. In: FERREIRA, Marieta de Moraes; AMADO, Janaína (org.). Usos e abusos da história oral. Rio de Janeiro: FGV, 1996, p. 183-191.

DUMONT, Louis. Gênese, II - A categoria política e o Estado a partir do século XVIII. In: O individualismo: uma perspectiva antropológica da ideologia moderna. Rio de Janeiro: Rocco, 1985, p. 73-121.

GOFFMAN, Erving. Estigma: notas sobre a manipulação da identidade deteriorada. Rio de Janeiro: Zahar, 1978.

GORZ, André. Carta a D. - história de um amor. São Paulo: CosacNaify, 2012.

HALBWACHS, Maurice. A memória coletiva. São Paulo: Editora Revista dos Tribunais, 1990.

KLAWITER, Maren. The impact of disease regimes and social movements on illness experience. In: The biopolitics of breast cancer: changing cultures of disease and activism. Minnesota: University of Minnesota Press, 2008, p. 229-246.

MAUSS, Marcel. Uma categoria do espírito humano: a noção de pessoa e a de "eu". In: Sociologia e Antropologia. São Paulo: CosacNaify, 2003, p. 367-397.

ORTNER, Sherry. Poder e projetos: reflexões sobre a agência. In: GROSSI, Miriam; ECKERT, Cornélia; FRY, Peter. (org.). Conferências e diálogos: saberes e práticas antropológicas. Blumenau: Nova Letra, 2007, p. 45-80.

POLLAK, Michael. Memória, esquecimento, silêncio. Estudos Históricos, Rio de Janeiro, v. 2, n. 3, 1989. Disponível em:

http://www.uel.br/cch/cdph/arqtxt/Memoria_esquecimento_silencio.pdf. Acesso em: 30 mar. 2021.

POLLAK, Michael. Memória e identidade social. Estudos Históricos, Rio de Janeiro, v. 5, n.10, 1992. Disponível em:

http://www.pgedf.ufpr.br/memoria\%20e\%20identidadesocial\%20A\%20capraro\%202.pdf. Acesso em: 30 mar. 2021.

ARACNOIDITE. Portal São Francisco. [Sem data]. Disponível em:

https://www.portalsaofrancisco.com.br/saude/aracnoidite. Acesso em: 30 mar. 2021. 
SARLO, Beatriz. Tempo passado: cultura da memória e guinada subjetiva. São Paulo: Companhia das Letras; Belo Horizonte: UFMG, 2007.

SEIXAS, Heloísa. O lugar escuro: uma história de senilidade e loucura. Rio de Janeiro: Objetiva, 2007.

SIBILIA, Paula. O show do eu - a intimidade como espetáculo. Rio de Janeiro: Contraponto, 2016.

SPENCE, Jo. Cultural sniping: the art of transgression. New York: Routledge, 1995.

VELHO, Gilberto. Projeto, emoção e orientação em sociedades complexas. In:

Individualismo e cultura. Rio de Janeiro: Jorge Zahar, 1999, p. 15-37.

VELHO, Gilberto. Memória, identidade e projeto. In: Um antropólogo na cidade - ensaios de antropologia urbana. Rio de Janeiro: Zahar, 2013, p. 62-68.

Submetido em 30.09.2020

Aprovado em 09.11.2020 